\title{
Analisis Sosiodemografi terhadap Pemberian ASI Eksklusif di Provinsi Sulawesi Selatan : Analisis Data Susenas 2017
}

\section{Sociodemography Analysis of Exclusive Breastfeeding in South Sulawesi Province : Susenas Data Analysis, 2017}

\author{
Dwi Ayulestari*, Prastuti Soewondo \\ Fakultas Kesehatan Masyarakat, Universitas Indonesia, Depok, Indonesia \\ (*dwiayulestari.da@gmail.com)
}

\begin{abstract}
ABSTRAK
Menyusui merupakan kewajiban seorang ibu untuk memberikan hak anak mendapatkan nutrisi yang dibutuhkan untuk pertumbuhan dan perkembangan yang sehat. Penelitian ini adalah data sekunder Survei Sosial Ekonomi Nasional (Susenas) tahun 2017. Responden penelitian adalah seluruh ibu yang memiliki bayi usia 6-24 bulan di provinsi Sulawesi Selatan sebanyak 1.857 ibu. Binary Regression yaitu model Logit dan model Probit digunakan untuk menemukan probabilitas dari faktor sosiodemografi terhadap pemberian ASI eksklusif. Hasil penelitian diperoleh bahwa umur ibu berpengaruh negatif terhadap pemberian ASI eksklusif dengan nilai koefisien Logit $-0,105$ dan Probit $-0,600$ ( $p$ value $<0,01$ ). Hasil penelitian juga menunjukkan bahwa pendapatan rumah tangga berpengaruh positif terhadap pemberian ASI eksklusif dengan nilai koefisien Logit 0,645 dan Probit 0,376 ( $p$ value $<0,01$ ) begitupun dengan paritas yang berpengaruh positif terhadap pemberian ASI eksklusif dengan nilai koefisien Logit 1,210 dan Probit 0,713 ( $p$ value $<0,01$ ). Umur ibu merupakan faktor sosiodemografi terhadap pemberian ASI eksklusif, namun umur ibu menunjukkan pengaruh yang negatif. Sementara responden dengan pendapatan rumah tangga dan paritas menunjukkan pengaruh yang positif dan signifikan terhadap pemberian ASI ekslusif. Hal ini menunjukkan bahwa semakin tinggi umur ibu maka semakin tinggi peluang untuk tidak memberikan ASI eksklusif.
\end{abstract}

Kata kunci : Sosiodemografi, umur ibu, pendapatan rumah tangga, paritas

\section{ABSTRACT}

Breastfeeding is one of mother's responsibility to give children's need of nutrition for healthy growth and development. This research using secondary data from National Social Economic Survey 2017. The respondents was all mother with 6-24 month baby in South Sulawesi Province as many as 1.857 mothers. Binary regression with Logit Models and Probit Models was used to uncover the probability from factor sosiodemography to exclusive breastfeeding. The result showed that mother's age negatively related to exclusive breastfeeding with coefficient Logit value $-0,105$ and Probit value $-0,600$ ( $p$ value $<0,01$ ). The result also found that household income positively related to exclusive breastfeeding with coefficient Logit value 0,645 and Probit value 0,376 ( $p$ value $<0,01)$, the same with parity which positively related with coefficient Logit value 1,210 and Probit value 0,713 ( $p$ value $<0,01$ ). Mother's age was the factor sociodemography to exclusive breastfeeding, however mother's age showed negative effect. Moreover, respondents with household income and parity showed positive effect with exclusive breastfeeding. This conclude that the higher mother's age, the higher chance of mother to not giving exclusive breastfeeding.

Keywords : Sociodemography, mother's age, household income, parity 


\section{PENDAHULUAN}

Menyusui merupakan kewajiban seorang ibu untuk memberikan hak anak mendapatkan nutrisi yang dibutuhkan untuk pertumbuhan dan perkembangan yang sehat. World Health Organization merekomendasikan pemberian ASI mulai dari bayi baru lahir hingga usia 6 bulan menyusui terus menerus bersama dengan makanan pendamping yang sesuai hingga usia dua tahun atau lebih. ${ }^{1}$ Malnutrisi pada anak salah satunya diakibatkan karena kurangnya pemberian ASI eksklusif, karena itu seperempat kematian anak usia di bawah lima tahun. Sedangkan sepertujuh lainnya mengalami gizi kurang karena tidak memperoleh nutrisi yang maksimal. Nutrisi pada masa awal kelahiran bayi menjadi hal yang sangat penting untuk kesehatan dan tumbuh kembang bayi. ${ }^{2}$ Sesuai dengan kebijakan yang dikeluarkan oleh Pemerintah Indonesia dalam Peraturan Pemerintah Nomor 33 Tahun 2012 untuk mendukung pemberian ASI eksklusif.

Meskipun penelitian lainnya menunjukkan ASI eksklusif dapat mengurangi angka kematian balita sebesar $11,6 \%$, tetapi cakupan pemberian ASI eksklusif masih relatif rendah secara global, seperti di Sub Sahara Afrika yaitu 35\%. ${ }^{3}$ Data tahun 2018 di Indonesia cakupan pemberian ASI eksklusif kurang dari 6 bulan yaitu 37,3\%. ${ }^{4}$ Dari 34 provinsi, Provinsi Sulawesi Selatan tergolong rendah yaitu $40,0 \%$ sedangkan target nasional yaitu $80,0 \% .{ }^{5}$ Berdasarkan data yang didapatkan pada tahun 2016 cakupan pemberian ASI ekslusif terendah di kabupaten/kota Gowa (24,07\%), Palopo $(33,17 \%)$ dan Jeneponto $(50,20 \%) .{ }^{6}$ Rendahnya pemberian ASI eksklusif disebabkan ketidakmampuan ibu mengatasi masalah menyusui pada periode awal karena beberapa faktor diantaranya pekerjaan dan pendapatan. ${ }^{7}$

Beberapa penelitian lainnya mengidentifikasi faktor-faktor yang mempengaruhi pemberian ASI eksklusif pada ibu. Pendidikan ibu adalah faktor yang signifikan dalam penelitian yang dilakukan di Ghana, tetapi ini bukan prediktor di South Ethiopia. ${ }^{8} 9$ Umur mempengaruhi pemberian ASI eksklusif, tetapi tidak untuk praktik menyusui eksklusif di Nepal. ${ }^{10,11}$ Sebuah penelitian yang dilakukan di Afrika menunjukkan bahwa paritas adalah faktor yang signifikan terhadap pemberian ASI eksklusif, tetapi tidak signifikan pada peneli- tian di United States. ${ }^{12,13}$

Berbagai jenis penelitian di Sulawesi Selatan masih memiliki cakupan pemberian ASI eksklusif yang rendah. Penelitian oleh Ida Leida dan Rahmatillah menemukan bahwa cakupan pemberian ASI eksklusif oleh ibu multipara di Kabupaten Jeneponto cukup rendah yaitu $26,3 \%$ dan dipengaruhi oleh pengetahuan dan informasi dari petugas kesehatan. ${ }^{14} \mathrm{Hal}$ ini menjadi ma-salah karena saat ini informasi menyusui eksklusif sangat mudah untuk didapatkan. Beberapa faktor internal ibu, tenaga kesehatan, iklan susu formula serta faktor pelayanan kesehatan berdampak pada pemberian ASI eksklusif. Berdasarkan latar belakang tersebut, mendorong peneliti untuk mengetahui faktor-faktor yang mempengaruhi pemberian ASI sksklusif di provinsi Sulawesi Selatan berdasarkan variabel sosiodemografi.

\section{BAHAN DAN METODE}

Desain penelitian ini adalah cross sectional study. Jenis data yang digunakan dalam penelitian ini adalah data sekunder Survei Sosial Ekonomi Nasional (Susenas) tahun 2017. Populasi Susenas 2017 yang digunakan yaitu Provinsi Sulawesi Selatan dari 24 kabupaten/kota. Sampel dalam penelitian ini adalah seluruh ibu wanita usia subur yang meiliki bayi usia 6-24 bulan dengan kriteria menyusui selama 6 bulan sebanyak $1.857 \mathrm{ibu}$. Data dianalisis secara univariat, bivariat, dan multivariat yang menggunakan model Binary Regression melalui metode analisis regresi Logit dan Probit. Analisis menggunakan aplikasi STATA 15.0.

\section{HASIL}

Total responden dalam penelitian yaitu $1.857 \mathrm{ibu}$, cakupan pemberian ASI eksklusif di provinsi Sulawesi Selatan tahun 2017 yaitu sebesar $21,6 \%$. Hasil analisis univariat menunjukkan kelompok umur responden paling banyak terdapat pada kelompok umur 15-34 tahun yaitu sebanyak $1.375 \mathrm{ibu}(74,04 \%)$ dan tingkat pendidikan responden paling banyak di tingkat rendah (SD-SMP) yaitu sebanyak 949 ibu (51,10\%). Status pekerjaan yang paling banyak adalah tidak bekerja yaitu $1.375(74,04 \%)$ dan memiliki anak $>1$ yaitu 1.268 ibu $(68,28 \%)$. Sebagian besar responden memiliki pendapatan rumah tangga $\geq$ UMP yaitu $1.075 \mathrm{ibu}$ $(57,89 \%)$. Penolong persalinan responden paling 
Tabel 1. Distribusi Sosiodemografi Responden

\begin{tabular}{|c|c|c|}
\hline Variabel & $\mathrm{n}=\mathbf{1 8 5 7}$ & $\%$ \\
\hline \multicolumn{3}{|l|}{ Variabel Dependen } \\
\hline \multicolumn{3}{|l|}{ ASI eksklusif } \\
\hline Ya & 402 & 21,65 \\
\hline Tidak & 1.455 & 78,35 \\
\hline \multicolumn{3}{|l|}{ Variabel Independen } \\
\hline \multicolumn{3}{|l|}{ Kelompok Umur (tahun) } \\
\hline $15-34$ & 1375 & 74,04 \\
\hline$\geq 35$ & 482 & 25,96 \\
\hline \multicolumn{3}{|l|}{ Tingkat Pendidikan } \\
\hline Rendah (SD-SMP) & 949 & 51,10 \\
\hline Tinggi (SMA-PT) & 908 & 48,90 \\
\hline \multicolumn{3}{|l|}{ Status Pekerjaan } \\
\hline Tidak Bekerja & 1.234 & 66,45 \\
\hline Bekerja & 623 & 33,55 \\
\hline \multicolumn{3}{|l|}{ Pendapatan RT } \\
\hline$<$ UMP & 782 & 42,11 \\
\hline$\geq \mathrm{UMP}$ & 1.075 & 57,89 \\
\hline \multicolumn{3}{|l|}{ Paritas } \\
\hline 1 & 589 & 31,72 \\
\hline$>1$ & 1.268 & 68,28 \\
\hline \multicolumn{3}{|l|}{ Penolong Persalinan } \\
\hline Tenaga Kesehatan & 1.769 & 95.26 \\
\hline Bukan Tenaga Kesehatan & 88 & 4,74 \\
\hline \multicolumn{3}{|l|}{ Penggunaan Alat Kontrasepsi } \\
\hline Tidak & 457 & 24,61 \\
\hline Ya & 1.400 & 75,39 \\
\hline
\end{tabular}

banyak dibantu oleh tenaga kesehatan yaitu 1.769 ibu $(95,26 \%)$ dan banyak yang menggunakan alat kontrasepsi yaitu $1.400 \mathrm{ibu}(75,39 \%)$ (Tabel 1).

Hasil analisis bivariat antara variabel independen dengan variabel dependen pemberian ASI eksklusif menunjukkan sebagian besar responden yang memiliki umur 15-34 tahun memberikan ASI eksklusif yaitu sebesar 364 ibu $(26,47 \%)$ dibandingkan dengan responden yang memiliki umur $\geq 35$ tahun yaitu $38 \mathrm{ibu}(7,88 \%)$. Sebanyak $246 \mathrm{ibu}$ $(27,09 \%)$ yang memiliki tingkat pendidikan tinggi (SMA-PT) memberikan ASI eksklusif dibandingkan dengan ibu yang memiliki tingkat pendidikan rendah (SD-SMP) yaitu 156 ibu (16,44\%). Status pekerjaan responden yang lebih banyak memberikan ASI eksklusif adalah yang tidak bekerja yaitu $281 \mathrm{ibu}(22,77 \%)$ dibandingkan ibu yang bekerja yaitu $121 \mathrm{ibu}(19,42 \%)$. Responden yang memiliki anak satu lebih banyak memberikan ASI eksklusif yaitu $240 \mathrm{ibu}(40,75 \%)$ dibandingkan dengan ibu yang memiiliki anak $>1$ yaitu 162 ibu (12,78\%). Pendapatan rumah tangga responden $\geq$ UMP le- bih banyak memberikan ASI eksklusif yaitu 272 ibu $(25,30 \%)$ dibandingkan pendapatan rumah tangga <UMP yaitu 130 ibu (16,62\%). Sebanyak $382 \mathrm{ibu}(21,59 \%)$ yang memberikan ASI eksklusif penolong persalinannya adalah tenaga kesehatan dibandingkan yang bukan tenaga kesehatan yaitu $20 \mathrm{ibu}(22,73 \%)$. Responden yang menggunakan alat kontrasepsi lebih banyak memberikan ASI eksklusif yaitu $273 \mathrm{ibu}(19,50 \%)$ dibandingkan yang tidak menggunakan alat kontrasepsi yaitu $129 \mathrm{ibu}$ (28,23\%) (Tabel 2).

Analisis multivariat menyajikan probabilitas dan analisis hubungan antara antara satu variabel dependen dengan beberapa variabel independen berupa data kualitatif dikotomi pada dua model. Dengan taraf signifikansi $1 \%, 5 \%$ dan $10 \%$ jika $p$-value $0,01,0,05$ atau 0,1 maka variabel tersebut secara signifikan mempengaruhi variabel dependen. Hasil analisis pada model Logit dan Probit menunjukkan bahwa umur ibu yang berusia $\geq 35$ tahun memiliki kemungkinan lebih kecil untuk memberikan ASI eksklusif dibandingkan ibu yang berumur 15-34 tahun dan umur ibu berpengaruh negatif terhadap pemberian ASI eksklusif dengan nilai koefisien Logit $-0,105$ dan Probit $-0,600$ ( $p$ value $<0,01$ ). Variabel tingkat pendidikan ibu yang memiliki tingkat pendidikan tinggi SMA sampai Perguruan Tinggi memiliki kemungkinan lebih besar untuk memberikan ASI Eksklusif dibandingkan dengan ibu yang mempunyai tingkat pendidikan rendah SD sampai SMA, tetapi tingkat pendidikan tidak memiliki pengaruh terhadap pemberian ASI eksklusif nilai koefisien Logit 0,227 dan Probit 0,138 ( $p$ value $>0,1$ ) (Tabel 3).

Variabel status pekerjaan pada ibu yang bekerja memiliki kemungkinan lebih kecil untuk memberikan ASI eksklusif dibandingkan ibu yang tidak bekerja, tetapi status pekerjaan ibu bekerja tidak memiliki pengaruh terhadap pemberian ASI eksklusif nilai koefisien Logit $-0,166$ dan Probit $-0,085$ ( $p$ value $>0,1$ ). Sedangkan variabel pendapatan rumah tangga $\geq$ UMP memiliki pengaruh positif terhadap pemberian ASI eksklusif dengan nilai koefisien Logit 0,645 dan Probit 0,376 dan $(p$ value $<0,01)$. Begitupun variabel paritas bahwa Ibu yang memiliki jumlah anak yang dilahirkan 1 memiliki kemungkinan lebih besar untuk memberikan ASI eksklusif daripada ibu yang memiliki anak $>1$ dengan nilai koefisien 
Tabel 2. Determinan Pemberian ASI Eksklusif di Provinsi Sulawesi Selatan

\begin{tabular}{|c|c|c|c|c|c|c|}
\hline \multirow{3}{*}{ Variabel } & \multicolumn{4}{|c|}{ ASI Eksklusif } & \multirow{2}{*}{\multicolumn{2}{|c|}{ Total }} \\
\hline & \multicolumn{2}{|c|}{ Tidak ASI Eksklusif } & \multicolumn{2}{|c|}{ ASI Eksklusif } & & \\
\hline & $\mathrm{n}$ & $\%$ & $\mathbf{n}$ & $\%$ & $\bar{n}$ & $\%$ \\
\hline \multicolumn{7}{|l|}{ Kelompok Umur (tahun) } \\
\hline$\geq 35$ & 444 & 92,12 & 38 & 7,88 & 482 & 100 \\
\hline $15-34$ & 1.011 & 78,53 & 364 & 26,47 & 1.375 & 100 \\
\hline \multicolumn{7}{|l|}{ Tingkat Pendidikan } \\
\hline Rendah (SD-SMP) & 793 & 83,56 & 156 & 16,44 & 949 & 100 \\
\hline Tinggi (SMA-PT) & 662 & 72,91 & 246 & 27,09 & 908 & 100 \\
\hline \multicolumn{7}{|l|}{ Status Pekerjaan } \\
\hline Bekerja & 502 & 80,58 & 121 & 19,42 & 623 & 100 \\
\hline Tidak Bekerja & 953 & 77,23 & 281 & 22,77 & 1.234 & 100 \\
\hline \multicolumn{7}{|l|}{ Pendapatan RT } \\
\hline$<\mathrm{UMP}$ & 652 & 83,36 & 130 & 16,62 & 782 & 100 \\
\hline$\geq \mathrm{UMP}$ & 803 & 74,70 & 272 & 25,30 & 1.075 & 100 \\
\hline \multicolumn{7}{|l|}{ Paritas } \\
\hline$>1$ & 1.106 & 87,22 & 162 & 12,78 & 1.268 & 100 \\
\hline 1 & 349 & 59,25 & 240 & 40,75 & 589 & 100 \\
\hline \multicolumn{7}{|l|}{ Penolong Persalinan } \\
\hline Bukan Tenaga Kesehatan & 68 & 77,27 & 20 & 22,73 & 88 & 100 \\
\hline Tenaga Kesehatan & 1.387 & 78,41 & 382 & 21,59 & 1.769 & 100 \\
\hline \multicolumn{7}{|l|}{ Penggunaan Alat Kontrasepsi } \\
\hline Tidak & 328 & 71,77 & 129 & 28,23 & 457 & 100 \\
\hline $\mathrm{Ya}$ & 1.127 & 80,50 & 273 & 19,50 & 1.400 & 100 \\
\hline
\end{tabular}

Logit 1,210 dan Probit 0,713 ( $p$ value $<0,01$ ) (Tabel 3).

Variabel penolong persalinan pada ibu yang melahirkan dengan bantuan penolong persalinan tenaga kesehatan memiliki kemungkinan lebih besar untuk memberikan ASI eksklusif daripada ibu yang melahirkan dengan penolong persalinan bukan tenaga kesehatan, tetapi penolong persalinan tenaga kesehatan tidak ada pengaruh terhadap pemberian ASI eksklusif nilai koefisien Logit $-0,496$ dan Probit $-0,290,(p$ value $>0,1)$. Hal yang sama dengan variabel penggunaan alat kontrasepsi pada ibu yang tidak menggunakan alat kontrasepsi saat menyusui memiliki kemungkinan lebih besar memberikan ASI eksklusif kepada anaknya tidak memiliki pengaruh penggunaan alat kontrasepsi terhadap pemberian ASI eksklusif nilai koefisien Logit 0,007 dan Probit 0,011 ( $p$ value $>0,01$ ) (Tabel 3).

\section{PEMBAHASAN}

Penelitian ini menunjukkan tingkat pemberian ASI eksklusif yang rendah di Provinsi Sulawesi Selatan. Ibu yang memberikan ASI eksklusif ada- lah sebanyak $21,65 \%$, belum memenuhi target $\mathrm{Na}$ sional yaitu sebesar $80 \%$. Penelitian ini memungkinkan untuk mengevaluasi tingkat pemberian ASI eksklusif dan dapat menentukan faktor ibu tidak menyusui atau penghentian ibu memberikan ASI eksklusif kepada bayinya. Dalam analisis regresi menunjukkan variabel yang secara signifikan mempengaruhi pemberian ASI eksklusif yaitu variabel umur ibu, pendapatan RT dan paritas.

Umur ibu memiliki hubungan yang signifikan terhadap pemberian ASI eksklusif, umur 15-34 tahun memiliki peluang lebih besar memberikan ASI eksklusif. Hal ini didorong oleh faktor fisiologis ibu yang lebih memungkinkan untuk menyusui eksklusif, karena fisik ibu umur $\geq 35$ tahun lebih lemah dari pada ibu usia muda sehingga kemampuan atau produktivitas asi menurun. Hasil penelitian menunjukkan pengaruh yang signifikan umur ibu dengan pemberian ASI eksklusif. Berdasarkan penelitian yang dilakukan Tampah Naah menunjukkan bahwa pemberian ASI eksklusif lebih banyak dilakukan pada umur ibu 20-35 tahun. ${ }^{15}$ Hasil penelitian ini sejalan dengan penelitian Patel et al., menunjukkan terdapat hubungan 
Tabel 3. Perbandingan Hasil Uji Asumsi LPM, Logit dan Probit Variabel ASI Eksklusif terhadap Variabel Independen

\begin{tabular}{|c|c|c|c|c|c|c|}
\hline \multirow[b]{2}{*}{ Variabel } & \multirow{2}{*}{$\begin{array}{c}\text { LPM (OLS) } \\
\begin{array}{c}\text { Koefisien } \\
\text { (Robust) }\end{array} \\
\end{array}$} & \multicolumn{2}{|c|}{ Logit (MLE) } & \multicolumn{2}{|c|}{ Probit (MLE) } & \multirow[b]{2}{*}{$95 \% \mathrm{CI}$} \\
\hline & & $\begin{array}{l}\text { Koefisien } \\
\text { (Robust) }\end{array}$ & $\begin{array}{c}\text { Marginal } \\
\text { Effect }\end{array}$ & $\begin{array}{l}\text { Koefisien } \\
\text { (Robust) }\end{array}$ & $\begin{array}{c}\text { Marginal } \\
\text { Effect }\end{array}$ & \\
\hline Umur Ibu & $\begin{array}{c}-0,115^{* * *} \\
(0,021)\end{array}$ & $\begin{array}{c}-0,105^{* * *} \\
(0,243)\end{array}$ & $\begin{array}{l}-0,165 \\
(0,035)\end{array}$ & $\begin{array}{c}-0,600^{* * *} \\
(0,123)\end{array}$ & $\begin{array}{l}-0,162 \\
(0,032)\end{array}$ & $-1.34--0,60$ \\
\hline Tingkat Pendidikan & $\begin{array}{c}0,031 \\
(0,024)\end{array}$ & $\begin{array}{c}0,227 \\
(0,159)\end{array}$ & $\begin{array}{c}0,033 \\
(0,023)\end{array}$ & $\begin{array}{c}0,138 \\
(0,090)\end{array}$ & $\begin{array}{c}0,037 \\
(0,024)\end{array}$ & $0,12-0,63$ \\
\hline Status Pekerjaan & $\begin{array}{l}-0,022 \\
(0,024)\end{array}$ & $\begin{array}{l}-0,166 \\
(0,167)\end{array}$ & $\begin{array}{l}-0,024 \\
(0,023)\end{array}$ & $\begin{array}{l}-0,085 \\
(0,095)\end{array}$ & $\begin{array}{l}-0,022 \\
(0,024)\end{array}$ & $-0,44-0,09$ \\
\hline Pendapatan RT & $\begin{array}{l}0,094^{* * *} \\
(0,022)\end{array}$ & $\begin{array}{l}0,645^{* * *} \\
(0,153)\end{array}$ & $\begin{array}{c}0,093 \\
(0,021)\end{array}$ & $\begin{array}{l}0,376^{* * *} \\
(0,088)\end{array}$ & $\begin{array}{c}0,098 \\
(0,022)\end{array}$ & $0,23-0,74$ \\
\hline Paritas & $\begin{array}{l}0,225^{* * *} \\
(0,029)\end{array}$ & $\begin{array}{l}1,210^{* * * *} \\
(0,158)\end{array}$ & $\begin{array}{c}0,204 \\
(0,028)\end{array}$ & $\begin{array}{l}0,713^{* * *} \\
(0,091)\end{array}$ & $\begin{array}{c}0,210 \\
(0,028)\end{array}$ & $0,98-1,48$ \\
\hline Penolong Persalinan & $\begin{array}{l}-0,069 \\
(0,054)\end{array}$ & $\begin{array}{l}-0,496 \\
(0,331)\end{array}$ & $\begin{array}{l}-0,084 \\
(0,063)\end{array}$ & $\begin{array}{l}-0,290 \\
(0,193)\end{array}$ & $\begin{array}{l}-0,087 \\
(0,063)\end{array}$ & $-1,01-0,09$ \\
\hline $\begin{array}{l}\text { Penggunaan Alat } \\
\text { Kontrasepsi }\end{array}$ & $\begin{array}{c}0,002 \\
(0,028)\end{array}$ & $\begin{array}{c}0,007 \\
(0,176)\end{array}$ & $\begin{array}{c}0,001 \\
(0,026)\end{array}$ & $\begin{array}{c}0,011 \\
(0,100)\end{array}$ & $\begin{array}{c}0,002 \\
(0,027)\end{array}$ & $\begin{array}{l}-0,06-0,46 \\
-1,82--0,33\end{array}$ \\
\hline Constant & $\begin{array}{l}0,258^{* * *} \\
(0,068)\end{array}$ & $\begin{array}{l}-0,735 \\
(0,486)\end{array}$ & --- & $\begin{array}{c}-0,509^{* * *} \\
(0,270)\end{array}$ & $\begin{array}{l}--- \\
---\end{array}$ & --- \\
\hline Observation & 1,857 & 1,857 & --- & 1,857 & --- & --- \\
\hline Pseudo R-Squared & 0,120 & 0,118 & --- & 0,119 & --- & --- \\
\hline Correctly Classified & --- & 67,96 & --- & 67,85 & & \\
\hline $\begin{array}{l}\text { Hosmer-Lemeshow } \\
\text { Chi sq }\end{array}$ & --- & 46,38 & --- & 53,71 & --- & --- \\
\hline$P$ value Chi square & --- & 0,000 & --- & 0,000 & -- & --- \\
\hline Log Likelihood & --- & -1577 & --- & -1575 & --- & --- \\
\hline
\end{tabular}

yang signifikan antara umur ibu dengan pemberian ASI eksklusif. ${ }^{12}$

Faktor sosial ekonomi yaitu pendapatan rumah tangga menunjukkan pengaruh yang signifikan terhadap pemberian ASI eksklusif. Pendapatan rumah tangga $\geq$ UMP akan berpeluang meningkatkan pemberian ASI eksklusif. Berdasarkan penelitian Hunegnaw et al., di Northwest Ethiopia menunjukkan bahwa pendapatan rumah tangga yang tinggi lebih banyak memberikan ASI eksklusif dibandingan pendapatan rumah tangga menengah dan rendah. Rumah tangga dengan pendapatan $\geq$ UMP lebih dimungkinkan untuk dapat memenuhi kebutuhan menyusui diantaranya makanan sehat seimbang, lingkungan yang sehat, alat memerah dan penyimpanan ASI walaupun oleh ibu yang bekerja serta mampu mendapatkan informasi dari media elektronik seperti smartphone terkait kegunaan pemberian ASI eksklusif. ${ }^{16}$ Hasil penelitian ini sejalan dengan penelitian
Shifraw et al., pada ibu di daerah perkotaan Ethiopia menunjukkan hubungan yang signifikan antara pendapatan terhadap pemberian ASI eksklusif. ${ }^{17}$

Paritas ibu terhadap pemberian ASI eksklusif memiliki hubungan yang signifikan, anak yang dilahirkan pertama dan kedua mempunyai kemungkinan mendapat ASI eksklusif lebih tinggi dari pada anak ketiga dan seterusnya. Ibu yang melahirkan anak pertama dan kedua memiliki usia yang masih relatif lebih muda dan menginginkan untuk anak pertamanya mendapatkan nutrisi terbaik. Ibu usia muda lebih mudah mencari informasi terkait ASI eksklusif baik dari media cetak, elektronik, dukungan petugas kesehatan dan dukungan keluarga. Hasil penelitian menunjukkan pengaruh yang signifikan dengan pemberian ASI eksklusif. Hasil penelitian ini sejalan penelitian Patel et al., yang menunjukkan di wilayah Afrika pemberian ASI eksklusif lebih banyak dilakukan pada paritas 1-2 dan memiliki hubungan yang signifikan ter- 
hadap pemberian ASI eksklusif. ${ }^{12}$

Ibu yang memiliki pendidikan tinggi yaitu SMA sampai dengan Perguruan Tinggi mempunyai kemungkinan lebih besar dalam memberikan ASI eksklusif. Semakin tinggi pendidikan formal ibu maka semakin banyak mendapatkan informasi terkait dengan pemberian ASI eksklusif. Sementara ibu yang berpendidikan rendah dan memilih untuk bekerja dan beraktivitas di luar rumah lebih memungkinkan mengganti ASI dengan air putih, teh atau susu formula karena mereka tidak memahami manfaat dan khasiat asi eksklusif. Ibu berpendidikan rendah diduga lebih mengikuti kepercayaan tradisi keluarga jaman dahulu di mana sebelum usia 6 bulan anak sudah mendapatkan makanan padat akibat kurangnya informasi. Hasil penelitian ini menunjukkan tidak ada pengaruh yang signifikan antara tingkat pekerjaan terhadap pemberian ASI eksklusif. Hasil penelitian ini sejalan dengan penelitian Jara-Palacious et al., yang menunjukkan tidak ada hubungan pendidikan ibu terhadap pemberian ASI eksklusif. ${ }^{18}$

Status pekerjaan merupakan salah satu faktor penyebab ibu tidak memberikan ASI eksklusif yaitu pada ibu bekerja. Hasil penelitian menunjukkan tidak ada pengaruh yang signifikan antara status pekerjaan dengan pemberian ASI eksklusif. Hal ini disebabkan oleh sebagian besar pada penelitian ini ibu memiliki status pekerjaan tidak bekerja. Kategori pekerjaan juga sangat tidak bervariasi misalnya jenis pekerjaan informal atau non informal dan bekerja di rumah (IRT) atau di luar rumah agar bisa mendapatkan gambaran atau potret pengaruh ibu bekerja terhadap pemberian ASI eksklusif. Berdasarkan penelitian Shifraw et al., ibu yang tidak bekerja lebih banyak memberikan ASI eksklusif. ${ }^{17}$ Hasil penelitian ini sejalan dengan penelitian Jara-Palacios et al., yang menunjukkan tidak ada hubungan antara status pekerjaan dengan pemberian ASI eksklusif.

Pertolongan tenaga kesehatan saat melahirkan juga menjadi variabel yang tidak berpengaruh secara signifikan terhadap pemberian ASI eksklusif. Sebagian besar ibu penolong persalinannya adalah tenaga kesehatan. Hal ini dapat dipengaruhi oleh penolong persalinan baik dokter atau bidan lebih mempromosikan pemberian susu formula, sehingga banyak ibu memberikan susu formula saat setelah melahirkan. Begitupun de- ngan penolong persalinan bukan tenaga kesehatan yang memberikan air putih, teh dan air tajin pada bayi saat setelah dilahirkan karena dipengaruhi oleh tingkat kepercayaan bahwa keehatan fisik ibu belum memungkinkan untuk keluarnya ASI. Hasil penelitian ini tidak sesuai dengan teori Notoatmodjo bahwa penolong persalinan oleh tenaga kesehatan dapat memberikan informasi ASI eksklusif sehingga ibu lebih mengetahui tentang manfaat ASI dan memahami keuntungan menyusui secara eksklusif. Hasil penelitian ini sejalan dengan penelitian Patel et al., ${ }^{12}$ yang menunjukkan tidak adanya hubungan yang signifikan antara penolong persalinan dengan pemberian ASI eksklusif.

Pemberian ASI secara eksklusif merupakan cara alami bagi ibu pasca melahirkan untuk berKB. Hasil penelitian menunjukkan tidak ada pengaruh yang signifikan antara status penggunaan alat kontrasepsi dengan pemberian ASI eksklusif. Hal ini disebabkan sebagian besar pada penelitian ini ibu menggunakan alat kontrasepsi. Banyak di antaranya ibu memakai kontrasepsi karena menganggap kb alami dengan menyusui secara eksklusif tidak berhasil dalam mencegah kehamilan. Hasil penelitian ini sejalan dengan penelitian Puraningsih dan Wati ${ }^{20}$ menunjukkan bahwa ibu yang menggunakan KB suntik 3 bulan mempengaruhi ketidaklancaran ASI karena mempengaruhi hormon estrogen dan progesteron dimana hormon ini dapat mempengaruhi produksi ASI.

\section{KESIMPULAN DAN SARAN}

Ibu yang memberikan ASI eksklusif adalah sebanyak $21,65 \%$. Dalam analisis regresi menunjukkan variabel yang secara signifikan mempengaruhi pemberian ASI eksklusif yaitu variabel umur ibu, pendapatan RT dan paritas. Umur ibu merupakan faktor determinan terhadap pemberian ASI eksklusif, tetapi umur ibu menunjukkan pengaruh yang negatif. Sementara resonden dengan pendapatan rumah tangga dan paritas menunjukkan pengaruh yang positif dan signifikan dengan pemberian ASI ekslusif. Hal ini menunjukkan bahwa semakin tinggi umur ibu maka semakin kecil peluang untuk tidak memberikan ASI eksklusif.

Saran yang diberikan kepada pemerintah Provinsi Sulawesi Selatan agar lebih memperhatikan pendidikan khususnya pada perempuan baik diperkotaan maupun pedesaan, serta penyuluhan 
terhadap pernikahan dini yang saat ini menjadi trend di Provinsi Sulawesi Selatan akibatnya banyak yang memutuskan pendidikannya dan lebih memilih tinggal di rumah menjadi Ibu Rumah Tangga (IRT). Selain itu, perlu dilakukan evaluasi terhadap tenaga kesehatan dalam hal ini penolong persalinan untuk membantu ibu untuk menyusui dini setelah persalinan dan mempertahankan pemberian ASI meskipun ibu dipisah dari bayinya untuk mendukung pemberian ASI eksklusif. Untuk penelitian selanjutnya perlu pengkajian ulang dari beberapa variabel pada penelitian ini yang tidak menunjukkan hubungan sebagai faktor sosiodemografi terhadap pemberian ASI eksklusif dengan menggunakan metodologi yang berbeda seperti metode kualitatif.

\section{DAFTAR PUSTAKA}

1. WHO. Breastfeeding. WHO; 2018. [Online]. Available: http:/www.who.int/topics/breastfeeding/en/. [Accessed: 26-Nov-2018].

2. Kemenkes RI. Profil Kesehatan Indonesia 2016," in Profil Kesehatan Indonesia, Jakarta: Kementerian Kesehatan RI; 2016.

3. A. R. Maonga, M. J. Mahande, D. J. Damian, and S. E. Msuya. Factors Affecting Exclusive Breastfeeding among Women in Muheza District Tanga Northeastern Tanzania: A Mixed Method Community Based Study. Matern. Child Health J. 2016;20(1):77-87.

4. Kemenkes RI. Hasil Utama Riskesdas 2018. Jakarta : Kemenkes RI; 2018.

5. Riskesdas. Hasil Utama Riskesdas 2018, in Hasil Utama Riskesdas 2018. Jakarta: Riskesdas; 2018.

6. Dinkes Sulawesi Selatan. Profil Kesehatan Sulawesi Selatan 2017. Sulawesi Selatan: Dinkes Sulawesi Selatan; 2017.

7. T. Tewabe, A. Mandesh, T. Gualu, G. Alem, G. Mekuria, and H. Zeleke. Exclusive Breastfeeding Practice and Associated Factors among Mothers in Motta town, East Gojjam Zone, Amhara Regional State, Ethiopia, 2015 : A Cross-Sectional Study. 2017:1-7.

8. V. Mogre, M. Dery, and P. K. Gaa. Knowledge, Attitudes and Determinants of Exclusive Breastfeeding Practice among Ghanaian rural Lactating Mothers. Int. Breastfeed. J. 2016;11(1):1-9.
9. A. W. Kasahun, W. G. Wako, M. W. Gebere, and G. H. Neima. Predictors of Exclusive Breastfeeding Duration among 6-12 Month Aged Children in Gurage Zone, South Ethiopia : A Survival Analysis. Int. Breastfeed. J. 2017;12(20):1-10.

10. B. Teka, H. Assefa, and K. Haileslassie. Prevalence and Determinant Factors of Exclusive Breastfeeding Practices among Mothers in Enderta Woreda, Tigray, North Ethiopia: A Cross-Sectional Study. Int. Breastfeed. J. 2015;10(1):1-7.

11. R. Karkee, A. H. Lee, V. Khanal, and C. W. Binns. A Community-Based Prospective Cohort Study of Exclusive Breastfeeding in Central Nepal. BMC Public Health. 2014;14(1):16.

12. A. Patel et al. Rates and Determinants of Early Initiation of Breastfeeding and Exclusive Breast Feeding at 42 Days Postnatal in Six Low and Middle-Income Countries: A Pros- pective Cohort Study. Reprod. Health. 2015;12(2).

13. U. H. Nnebe-Agumadu, E. F. Racine, S. B. Laditka, and M. J. Coffman. Associations between Perceived Value of Exclusive Breastfeeding among Pregnant Women in the United States and Exclusive Breastfeeding to Three and Six Months Postpartum: A Prospective Study. Int. Breastfeed. J. 2016;11(1):1-11.

14. M. Thaha, Ida Leida and Rahmatillah Razak. Determinan Pemberian ASI Eksklusif oleh Ibu Multipara di Kabupaten Jeneponto. Jurnal MKMI; 2015;11(4):247-252.

15. A. M. Tampah-Naah and A. Kumi-Kyereme, Determinants of Exclusive Breastfeeding among Mothers in Ghana: A Cross-Sectional study. Int. Breastfeed. J. 2013;8(1):2-7.

16. M. T. Hunegnaw, L. D. Gezie, and A. S. Teferra. Exclusive Breastfeeding and Associated Factors among Mothers in Gozamin District, Northwest Ethiopia : A Community Based Cross-Sectional Study. Int. Breastfeed. J. 2017;12(1):1-9.

17. T. Shifraw, A. Worku, and Y. Berhane. Factors Associated Exclusive Breastfeeding Practices of Urban Women in Addis Ababa Public Health Centers, Ethiopia: A Cross Sectional Study Int. Breastfeed. J. 2015;10(1):4-9. 
18. M. A. Jara-Palacios, A. C. Cornejo, G. A. Peláez, J. Verdesoto, and A. A. Galvis. Prevalence and Determinants of Exclusive Breastfeeding among Adolescent Mothers from Quito, Ecuador: A Cross-Sectional Study. Int. Breastfeed. J. 2015;10(1):1-8.

19. S. Notoatmodjo. Kesehatan Masyarakat Ilmu dan Seni. Jakarta: Rineka Cipta; 2007.

20. E. Purwaningsih and R. S. Wati. Pengaruh Kontrasepsi Suntik terhadap Pengeluaran ASI eksklusif di BPS Triparyati Kemalang Kabupaten Klaten. J. Involusi Kebidanan. 2011:1(1):9-19. 